\title{
Coexistence of Central Diabetes Insipidus and Prolonged Cerebral Salt Wasting Syndrome after Brain Tumor Surgery: A Case Report
}

\author{
Ji Sun Lee, M.D. ${ }^{1}$ \\ Hee Jo Baek, M.D., Ph.D. ${ }^{2}$ \\ Chan Jong Kim, M.D., Ph.D. ${ }^{1}$ \\ Eun MiYang, M.D. ${ }^{1}$ \\ Department of Pediatrics', Chonnam \\ National University Hospital, Chonnam \\ National University Medical School, \\ Gwangju, Korea, Department of \\ Pediatrics ${ }^{2}$, Hwasoon Chonnam \\ National University Hospital, \\ Chonnam National University Medical \\ School, Hwasoon, Korea \\ Corresponding author: \\ Eun Mi Yang, M.D. \\ Department of Pediatrics, Chonnam \\ National University Hospital, 42 Jebong- \\ ro, Dong-gu, Gwangju 61469, Republic of \\ Korea \\ Tel: +82- 62-220-6647 \\ Fax: +82-62-222-6103 \\ E-mail:emyang@chonnam.ac.kr
}

Received: 29 January 2020

Revised: 27 February 2020

Accepted: 25 March 2020
Disturbances in water and salt balances are relatively common in children after brain tumor surgery. However, the coexistence of different diseases of water and sodium homeostasis is challenging to diagnose and treat. The coexistence of combined central diabetes insipidus (CDI) and cerebral salt wasting syndrome (CSWS) is rare and may impede accurate diagnosis. Herein, we report the case of an 18-year-old girl who underwent surgery for a germinoma and who presented prolonged coexistence of CDI and CSWS. The patient was diagnosed with panhypopituitarism with CDI at presentation and was treated with hydrocortisone, levothyroxine, and desmopressin. Postoperatively, she developed polyuria of more than $3 \mathrm{~L} /$ day, with a maximum daily urine output of $7.2 \mathrm{~L} /$ day. Her serum sodium level decreased from 148 to $131 \mathrm{mEq} / \mathrm{L}$. Polyuria was treated with desmopressin at incremental doses, and hyponatremia was managed with fluid replacement. At 2 months after surgery, she presented with hyponatremia-induced seizure. Polyuria and hyponatremia combined with natriuresis indicated CSWS. Treatment with fludrocortisone were initiated; then, her electrolyte level gradually normalized. CSWS is self-limiting and generally resolves within 2 weeks. However, the patient in this study still required treatment with vasopressin and fludrocortisone at 16-months after surgery. Hyponatremia in a patient with CDI may be erroneously interpreted as inadequate CDI control or syndrome of inappropriate antidiuretic hormone secretion, leading to inappropriate treatment. The identification of the potential combination of CDI and CSWS is important for early diagnosis and treatment.

Key words: Diabetes insipidus, Cerebral salt wasting, Hyponatremia, Polyuria

\section{Introduction}

Imbalance in fluid and electrolytes homeostasis is not rare in children after acute central nervous system (CNS) injury that particularly involves the pituitary gland $d^{1}$. Conditions, such as central diabetes insipidus (CDI), which can be transient or permanent and partial or complete, syndrome of inappropriate antidiuretic hormone secretion (SIADH), and cerebral salt wasting syndrome (CSWS) can occur in children with CNS injury ${ }^{2,3)}$. CDI is associated with hypernatremia, whereas SIADH and CSWS are correlated to hyponatremia ${ }^{4}$. Patients with CDI and CSWS can lead to polyuria; CDI causes free water loss, CSWS causes both water and salt loss. In contrast, patients with 
SIADH experience free water retention. Thus, a differential diagnosis is important due to varying treatments and prognoses for different conditions. Delayed and incorrect diagnosis and management of these patients are likely to result in severe mortality and morbidity.

As two different water homeostasis abnormalities can coexist, diagnosis is sometimes extremely challenging. Concomitant CDI and CSWS is a rare clinical finding ${ }^{5-8}$. Polyuria caused by CDI can obscure polyuria that results from CSWS, and numerous clinicians still consider SIADH as the primary differential diagnosis of hyponatremia in patients with acute illness ${ }^{5,9}$. When this condition occurs, the prognosis is unfavorable due to frequent misdiagnosis and/or incorrect sodium correction, thereby posing a diagnostic and therapeutic challenge ${ }^{8,10}$. Herein, we report the case of a patient with CDI and prolonged CSWS who was successfully treated.

\section{Case report}

A 18-year-old girl with amenorrhea for 2 years, galactorrhea, and progressive weight loss (from 63 to $45 \mathrm{~kg}$ ) visited the hospital. Brain magnetic resonance imaging (MRI) was conducted for the evaluation of amenorrhea, and results revealed a $6.3 \mathrm{~cm}$ multiloculated cystic and solid enhancing mass involving the right basal ganglia, right hypothalamus, pituitary stalk, pituitary gland, $3^{\text {rd }}$ ventricle, right anterior thalamus, and right frontal lobe and a $1.1 \mathrm{~cm}$ additional enhancing mass in the pineal gland, indicating off-midline and pineal germinoma (Fig. 1). She presented with polyuria, and her laboratory examination results were as follows: sodium (Na) level, $159 \mathrm{mEq} / \mathrm{L}$; plasma osmolality, $323 \mathrm{mOsm} / \mathrm{kg}$; urine specific gravity, $\leq 1.005$; urine osmolality, $216 \mathrm{mOsm} / \mathrm{kg}$. Moreover, the patient complained of thirst. The anterior pituitary hormonal profile showed low free T4 (0.546 [range 0.7-1.8] ng/dL), normal serum TSH (2.12 [range 0.2-4.2] ng/dL), low cortisol (3.6 [range 8-19] $\mu \mathrm{g} / \mathrm{dL}$ ), normal serum adrenocorticotropic hormone (34 [range 10-60] pg/mL), pre-pubertal gonadotropin (LH level: $<0.01 \mathrm{mIU} / \mathrm{mL}$, FSH level: $0.61 \mathrm{mIU} / \mathrm{mL}$ ) and elevated serum prolactin levels (41.3 [range 4.8-23.3] ng/mL). The patient was diagnosed with CDI and panhypopituitarism and was treated with 1-thyroxine, hydrocortisone, and desmopressin, and replacement therapy was begun 5 days before surgery. Fifteen hours after surgery, the patient presented with increased urine output, from a diuresis of 700 cc over $6 \mathrm{~h}$ to $1,900 \mathrm{cc}$ over $4 \mathrm{~h}(9 \mathrm{cc} / \mathrm{kg} / \mathrm{h})$. Thus the patient was treated with $200 \mathrm{mg}$ of hydrocortisone for $24 \mathrm{~h}$, and a total of 3,300 cc of intravenous plasma solution was administered within $24 \mathrm{~h}$. During this time, the patient's $\mathrm{Na}$ level increased from 148 to $153 \mathrm{mEq} / \mathrm{L}$. The patient was considered as inadequately controlled CDI; thus, a part from oral desmopressin, $15 \mathrm{U}$ of vasopressin was administered subcutaneously. On the second postoperative day, the patient presented with diuresis of 5,000 cc over $24 \mathrm{~h}$ $(4.7 \mathrm{cc} / \mathrm{kg} / \mathrm{h})$. Thus, she received treatment with desmopressin, 200mg of hydrocortisone for $24 \mathrm{~h}$, as well as 1,200 cc of intravenous fluids and 2,500 cc of oral fluids. The patient presented with hypernatremia, with a Na level at 147 $\mathrm{mEq} / \mathrm{L}$. After several days, the Na levels normalized, and intravenous isotonic saline infusion was continually admi-

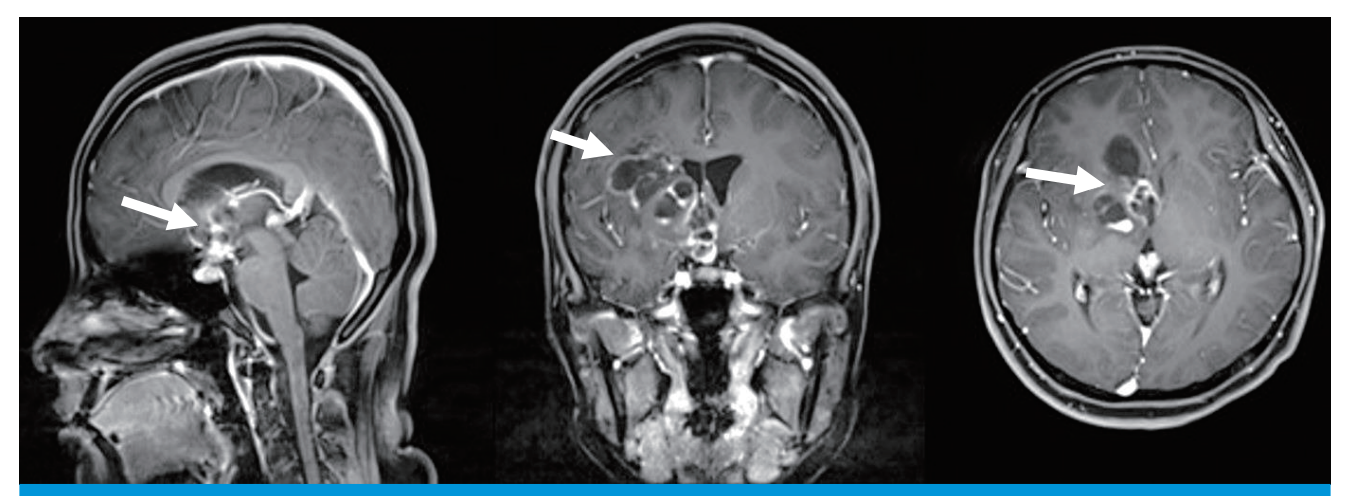

Fig. 1. Brain MRI in diagnosis. A $6.3 \mathrm{~cm}$, multiloculated cystic and solid enhancing mass involving right basal ganglia, right hypothalamus, pituitary stalk, pituitary gland, 3rd ventricle, right anterior thalamus, and right frontal lobe and a $1.1 \mathrm{~cm}$ additional enhancing mass in pineal gland, suggesting off-midline germinoma (white arrow) and pineal germinoma (white arrow). 
nistered. On day 8 , the patient underwent $1^{\text {st }}$ chemotherapy for 3 days. Massive vomiting occurred, and the clinical symptoms of dehydration persisted. Although the dose of desmopressin was increased, she still presented with polyuria $(7,210 \mathrm{cc}, 6.0 \mathrm{cc} / \mathrm{kg} / \mathrm{h})$ with a decrease in $\mathrm{Na}$ level from 148 to $125 \mathrm{mEq} / \mathrm{L}$ on day 13 . Hypernatremia improved after increasing the intravenous hypertonic fluid rate and hydrocortisone dose. Furthermore, the dose of oral desmopressin was increased up to $0.8 \mathrm{mg}$ per day with nasal desmopressin as needed. Two months after surgery, the patient received routine pre-chemotherapy hydration that is twice her maintenance rate and started $3^{\text {rd }}$ chemotherapy (intravenous carboplatin, $450 \mathrm{mg} / \mathrm{m}^{2}$ for 1 day, etoposide 150 $\mathrm{mg} / \mathrm{m}^{2}$ for 3 days). The patient presented with nausea and polyuria with slight dehydration. Ongoing treatment was required with high amounts of intravenous sodium supplementation. However, her serum Na level continually decreased below $135 \mathrm{mEq} / \mathrm{L}$ with high urinary losses (urine Na level: 34-201 mEq/L). With symptoms, such as polyuria and hyponatremia, the diagnosis of CDI combined with CSWS was considered. A plasma aldosterone level $<14.8$ (range: $30-160) \mathrm{pg} / \mathrm{mL}$ and renin activity at 0.06 [range: $0.32-1.84$ (supine)] ng/mL per hour were suppressed. Attempts at weaning the concentration and rate of hypertonic saline replacement were thwarted by hyponatremia and polyuria of up to $7 \mathrm{~L}$ per day $(6.9 \mathrm{~mL} / \mathrm{kg} / \mathrm{h})$. Fludrocorti- sone ( $0.05 \mathrm{mg}$ daily) treatment was initiated because it is effective as an adjunct treatment for CSWS. However, the patient still presented with hyponatremia, polyuria and natriuresis after the $4^{\text {th }}$ chemotherapy period. Despite the initiation of fludrocortisone, the patients' serum sodium level was $128 \mathrm{mmol} / \mathrm{L}$; urine output, was $5.5 \mathrm{~mL} / \mathrm{kg}$ per h; and urine sodium level, $38 \mathrm{mEql} / \mathrm{L}$. She presented a hyponatremic seizure which was treated with hypertonic saline (characterized by generalized tonic movement, 3 times a day, lasting about 2 to 3 minutes). In addition, the dose of fludrocortisone was gradually increased to a maximum of $0.3 \mathrm{mg}$ daily. Shortly thereafter, the serum Na level improved (145 mEq/L), and the urinary Na level decreased (Table 1). Her urinary volume subsequently normalized $(4 \mathrm{~mL} / \mathrm{kg} / \mathrm{h})$. The hypertonic fluid dose was gradually decreased. She was discharged from the hospital 19 days after the initiation of fludrocortisone and was treated with fludrocortisone 0.3 $\mathrm{mg}$ a day, orally desmopressin $0.8 \mathrm{mg} /$ day, hydrocortisone $25 \mathrm{mg} /$ day, and levothyroxine $50 \mathrm{mcg} /$ day. Treatment with fludrocortisone was continued at a dose of $0.3 \mathrm{mg}$ daily for another 5 months and was then decreased. Sixteen months after surgery, the patient still required oral desmopressin ( $0.5 \mathrm{mg} /$ day) and fludrocortisone $0.1 \mathrm{mg}$ per day along, with corticosteroids and, levothyroxine (50 mcg/day). Thus, the electrolyte level of the patient was maintained at normal. Follow-up brain MRI revealed that the germinoma had a

Table 1. The Related Data of the Patient before and after Surgery

\begin{tabular}{|c|c|c|c|c|c|c|c|c|}
\hline & $\begin{array}{l}\text { pre- } \\
\text { surgery }\end{array}$ & $\begin{array}{l}\text { Day of } \\
\text { surgery }\end{array}$ & $\begin{array}{l}1 \text { day post- } \\
\text { surgery }\end{array}$ & $\begin{array}{l}2 \text { day post- } \\
\text { surgery }\end{array}$ & $\begin{array}{l}13 \text { day post- } \\
\text { surgery }\end{array}$ & $\begin{array}{l}2 \text { month post- } \\
\text { surgery (start } \\
\text { fludrocortisone) }\end{array}$ & $\begin{array}{l}6 \text { month } \\
\text { post-surgery }\end{array}$ & $\begin{array}{l}16 \text { month } \\
\text { post-surgery }\end{array}$ \\
\hline Plasma sodium (mEq/L) & 158 & 148 & 153 & 147 & 125 & 127 & 125 & 142 \\
\hline Plasma osmolality (mOsm/Kg) & 323 & 297 & 311 & 306 & 245 & 261 & 256 & 287 \\
\hline Urinary sodium (mEq/L) & & & & & 51 & 136 & 97 & 85 \\
\hline Urinary osmolality (mOsm/kg) & 216 & & & 168 & 173 & 506 & 267 & 536 \\
\hline ACTH (pg/ml)/Cortisol (mcg/dL) & $34.5 / 3.5$ & & & & & $43 / 28.1$ & $23.7 / 9.7$ & \\
\hline TSH (ulU/ml)/Free T4 (ng/dL) & $2.12 / 0.546$ & $0.328 / 1.22$ & & & $0.064 / 1.37$ & $0.009 / 1.26$ & $0.013 / 1.21$ & $0.005 / 1.15$ \\
\hline $\begin{array}{l}\text { Renin activity }(\mathrm{ng} / \mathrm{mL} / \mathrm{hr}) / \\
\text { Aldosterone }(\mathrm{pg} / \mathrm{mL})\end{array}$ & & & & & $0.06 /<14.8$ & $0.12 / 47.8$ & $0.34 / 34.9$ & $0.64 / 35$ \\
\hline Plasma ADH & & & & & & 2.82 & 3.68 & \\
\hline Diuresis (ml/kg/h) & & & 9 & 4.7 & 6 & 4 & 2.4 & 2.2 \\
\hline Desmopressin & & & $\begin{array}{l}0.3 \mathrm{mg} / \text { day+ } \\
\text { nasal spray }\end{array}$ & $\begin{array}{l}0.3 \mathrm{mg} / \text { day+ } \\
\text { nasal spray }\end{array}$ & $\begin{array}{l}0.8 \mathrm{mg} / \text { day+ } \\
\text { nasal spray }\end{array}$ & 0.8 mg/day & $0.8 \mathrm{mg} /$ day & $0.5 \mathrm{mg} /$ day \\
\hline Hydrocortisone & $150 \mathrm{mg}$ iv & $100 \mathrm{mg}$ iv & 50 mg/day & 50 mg/day & 60 mg/day & 25 mg/day & 25 mg/day & 20 mg/day \\
\hline Fludrocortisone & & & & & & $\begin{array}{c}0.05 \mathrm{mg} / \text { day } \rightarrow \\
0.3 \mathrm{mg} / \text { day }\end{array}$ & $\begin{array}{c}0.2 \mathrm{mg} / \text { day } \rightarrow \\
0.3 \mathrm{mg} / \text { day }\end{array}$ & $0.1 \mathrm{mg} / \mathrm{day}$ \\
\hline
\end{tabular}

Abbreviations: ACTH, Adrenocorticotropic hormone; TSH, Thyroid stimulating hormone; Free T4, Free thyroxine; ADH, Antidiuretic hormone; iv, intravenous 
www.chikd.org

stable status for 16 months.

\section{Discussion}

Water and electrolyte imbalance are not rare in children with intracranial pathologies, such as tumors and head injury, that particularly involve the pituitary gland. Hyponatremia is common electrolyte disorder and is found in 8 to $35 \%$ of patients following pituitary surger $y^{4,7)}$. It can be associated with the SIADH, CSWS, treatment of CDI, and excessive fluid administration in patients with adipsia ${ }^{11)}$. Identical acute brain damage may cause either SIADH or CSWS. The clinical and biochemical features of both diseases are identical and the only discriminative feature is the volume status: it tends to be expanded in SIADH and low in CSWS $^{12)}$. CSWS is true hypernatremia and extracellular water loss due to inappropriate $\mathrm{Na}$ wasting in the urine, whereas SIADH is a dilutional hyponatremia caused by increased anti-diuretic hormone secretion ${ }^{13)}$. Symptoms of volume depletion (hypotension, increased heart rate, and weight loss) occur with CSWS, whereas symptoms of volume expansion occur with SIADH (decreased urine output and weight gain). Although determination of volume state is challenging to identify, CSWS can be differentiated from SIADH based on urine production ${ }^{12)}$. However, SIADH can coexist with CDI and in this case the excessive urine production secondary to natriuresis can be misinterpreted as poor control of CDI.

The different water homeostasis abnormalities may occur in isolation or may coexist with other conditions. Concomitant CDI and CSWS is rare and has been associated with a poor prognosis and increased mortality ${ }^{7,11)}$. This unfavorable prognosis is mainly attributed to the frequent misdiagnosis or incorrect correction of Na level. In our case, polyuria secondary to natriuresis is thought to be as inadequate CDI control and dose of desmopressin was increased which cause further deterioration in the degree of hyponatremia. Hyponatraemia in a patient with DI can be caused by water intoxication secondary to excessive desmopressin replacement, to coexistent CSW, to concurrent untreated or undertreated cortisol deficiency ${ }^{4}$, anticonvulsant treatment, or to a different source of sodium loss ${ }^{11}$. Excessive exogenous anti-diuretic hormone causes free water retention and results in dilutional hyponatremia due to oliguria ${ }^{12)}$. The patient developed extensive polyuria, indicating that the excessive dose of desmopressin was not the cause. And, panhypopituitarism was controlled with appropriate hormone replacement therapy, indicating that the cortisol deficiency was not the cause. Our patient receiving nephrotoxic chemotherapeutics in the treatment of brain tumor, it can be very difficult to distinguish CSWS from renal tubulopathy. The excessive degree of natriuresis compared to the degree of altered renal tubular threshold for phosphate and potassium reabsorption, and tubular protein leak should suggest that tubulopathy is not major cause ${ }^{11}$. In addition, aldosterone levels are typically suppressed in CSWS and normal or high in SIADH with plasma renin suppressed in both ${ }^{1)}$. Decreased plasma renin and aldosterone secretion in our patient could be suspected of CSWS. The presence of hyponatraemia and natriuresis in urinalysis collected while the patient develops polyuria (prior to desmopressin dose) with dehydration feature and recovery of hyponatremia after administration of water and sodium will also suggest CSWS. Finally, we diagnosed the patient with coexistence of CSWS and CDI.

The treatment of CSWS is to restore intravascular volume and serum sodium and normal saline is frequently used as an initial fluid ${ }^{1,12)}$. Once euvolemia is achieved, the degree of hyponatremia should be re-evaluated. If serum sodium levels are severely decreased $(<125 \mathrm{mEq} / \mathrm{L})$ or a large volume of intravenous fluid is required to maintain euvolemia, intravenous hypertonic saline can also be used ${ }^{13)}$. In addition, a mineralocorticoids also can be used to augment both serum sodium concentration and intravascular volume $\mathrm{e}^{14)}$. Most authors typically prescribe a dose of 0.1-0.2 mg per day, starting once the diagnosis of CSWS is made and continuing until $\mathrm{Na}$ concentration and water volume remain stably normal ${ }^{6}$. High-dose fludrocortisone $(0.2-0.4 \mathrm{mg} /$ day $)$ is often indicated in some patients with $\mathrm{CSWS}^{6,7)}$. It mediates a return to normal $\mathrm{Na}$ levels via a reduction in natriuresis by increasing Na reabsorption in the renal proximal tubule ${ }^{1,6)}$. The CSWS usually occurs within the first week after trauma, infection, or brain surgery and spontaneously resolves after 3-4 weeks ${ }^{7}$. Philipp et al. have shown that the onset of CSWS is within 2-3 days after trauma or cranial surgery, and the condition usually resolves within several weeks ${ }^{12)}$. Once the underlying cause 
of CSWS is corrected, it is usually considered a transient condition. In rare cases, patients present with long-term CSW that can last for months ${ }^{12,15)}$, particularly in the presence of CNS infection, cerebrospinal fluid obstruction, and tumor progression. Although the germinoma has a stable status in this study, the patient still required desmopressin and fludrocortisone to maintain normal $\mathrm{Na}$ level and diuresis at 16 months after surgery.

The patient presented with coexisting persistent CDI and prolonged CSWS, and the diagnosis and treatment were challenging. The identification of the potential combination of CDI and CSWS is important for early diagnosis and treatment.

\section{Acknowledgement}

Patient consent: This study was approved by the institutional review board (IRB), and the consent was waived due to the nature of the retrospective study [IRB number CNUH-EXP-2019-373].

\section{Disclosure}

This study was supported by a grant (CRI18024-1) from Chonnam National University Hospital Biomedical Institute.

\section{Conflicts of interest}

No potential conflict of interest relevant to this article was reported.

\section{ORCID}

JI Sun Lee https://orcid.org/0000-0002-4798-0769

Hee Jo Baek https://orcid.org/0000-0003-2301-9823

Eun Mi Yang http://orcid.org/0000-0001-9410-5855

Chan Jong Kim http://orcid.org/0000-0001-6519-2427

\section{References}

1. Edate S, Albanese A. Management of electrolyte and fluid disorders after brain surgery for pituitary/suprasellar tumours. Horm Res Paediatr 2015;83:293-301.

2. John CA, Day MW. Central neurogenic diabetes insipidus, syndrome of inappropriate secretion of antidiuretic hormone, and cerebral salt-wasting syndrome in traumatic brain injury. Crit Care Nurse 2012;32:e1-7.

3. Kiran Z, Sheikh A, Momin SN, Majeed I, Awan S, Rashid O, et al. Sodium and water imbalance after sellar, suprasellar, and parasellar surgery. Endocr Pract 2017;23:309-17.

4. Sperling MA. Pediatric Endocrinology. 4th ed. Philadelphia: Elsevier Saunders, 2014

5. Ferry RJ, Jr., Kesavulu V, Kelly A, Levitt Katz LE, Moshang T, Jr. Hyponatremia and polyuria in children with central diabetes insipidus: challenges in diagnosis and management. J Pediatr 2001; 138:744-7.

6. Taplin CE, Cowell CT, Silink M, Ambler GR. Fludrocortisone therapy in cerebral salt wasting. Pediatrics 2006;118:e1904-8.

7. Costa MM, Esteves C, Castedo JL, Pereira J, Carvalho D. A challenging coexistence of central diabetes insipidus and cerebral salt wasting syndrome: a case report. J Med Case Rep 2018;12:212.

8. Laredo S, Yuen K, Sonnenberg B, Halperin ML. Coexistence of central diabetes insipidus and salt wasting: the difficulties in diagnosis, changes in natremia, and treatment. J Am Soc Nephrol 1996;7:2527-32.

9. Schwartz WB, Bennett W, Curelop S, Bartter FC. A syndrome of renal sodium loss and hyponatremia probably resulting from inappropriate secretion of antidiuretic hormone. Am J Med 1957; 23:529-42

10. Wu X, Zhou X, Gao L, Wu X, Fei L, Mao Y, et al. Diagnosis and Management of Combined Central Diabetes Insipidus and Cerebral Salt Wasting Syndrome After Traumatic Brain Injury. World Neurosurg 2016;88:483-7.

11. Albanese A, Hindmarsh P, Stanhope R. Management of hyponatraemia in patients with acute cerebral insults. Arch Dis Child 2001;85:246-51.

12. von Bismarck P, Ankermann T, Eggert P, Claviez A, Fritsch MJ, Krause MF. Diagnosis and management of cerebral salt wasting (CSW) in children: the role of atrial natriuretic peptide (ANP) and brain natriuretic peptide (BNP). Childs Nerv Syst 2006;22:1275-81.

13. Yee AH, Burns JD, Wijdicks EF. Cerebral salt wasting: pathophysiology, diagnosis, and treatment. Neurosurg Clin N Am 2010;21: 339-52.

14. Oh JY, Shin Jl. Syndrome of Inappropriate Antidiuretic Hormone Secretion and Cerebral/Renal Salt Wasting Syndrome: Similarities and Differences. Front Pediatr 2015;22:146.

15. López de Lara D, Joyanes B, Llaneza A, Pérez O, Llorente B, Runkle I. Prolonged coexistent central diabetes insipidus and cerebral salt wasting syndrome following neurosurgery. Open Journal of Pediatrics 2013;3:74-7. 